\title{
UTILIZAÇÃO DE ELETRODO DE LEITO FIXO NO TRATAMENTO DE EFLUENTE TÊXTIL POR ELETROCOAGULAÇÃO
}

\author{
C. C. SEKI ${ }^{1}$, D. C. SILVA ${ }^{1}$, A. ARGONDIZO ${ }^{2}$ e A. P. SILVA ${ }^{2}$ \\ ${ }^{1}$ discente do curso de Engenharia Química na Universidade Federal de São Paulo \\ 2 docente da Universidade Federal de São Paulo, Departamento de Engenharia Química \\ E-mail para contato: alessandra.silva@unifesp.br
}

\begin{abstract}
RESUMO - Este trabalho teve por objetivo a avaliação do uso de reator eletroquímico com anodo de leito fixo constituído por partículas esféricas de ferro no tratamento de efluente têxtil simulado por eletrocoagulação. Foram avaliados os efeitos de $\mathrm{pH}$ e distância entre eletrodos sobre as respostas eficiência de remoção de cor e consumo energético. $\mathrm{O}$ reator mostrou-se bastante eficiente no tratamento de efluente têxtil simulado, obtendo-se percentuais de remoção do corante superiores a $90 \%$ com tempo de operação entre 15 e 30 minutos. Para o menor valor de distância e pH ácido obteve-se as maiores porcentagens de remoção de corante com menor tempo de operação, contudo, o menor consumo energético e consequente menor custo energético foi obtido para o $\mathrm{pH}$ básico com maior distância entre os eletrodos.
\end{abstract}

\section{INTRODUÇÃO}

A poluição das águas por efluentes industriais tem sido motivo de preocupação já há algum tempo. Dentre os setores industriais, o têxtil apresenta elevado potencial poluidor em razão do elevado consumo de corantes utilizados na etapa de tingimento e ao consumo de aditivos durante as etapas de pré-tingimento e armazenagem (Kunz, 2002). No quadro geral de indústrias no Brasil, o setor têxtil tem grande participação na atividade industrial sendo então um grande gerador de efluentes. Em 2015, foi responsável por 5,7\% do faturamento total da indústria de transformação brasileira, e a produção média têxtil foi de 1,9 milhão de toneladas em 2015 (ABIT, 2016). Frente a este elevado volume produtivo, é de fundamental importância garantir adequado tratamento aos rejeitos desse setor industrial.

Dentre as várias tecnologias disponíveis para tratamento de efluentes líquidos, a eletrocoagulação (ou eletrofloculação) tem sido objeto de muitos estudos (Formentini, 2012; Kiliç e Hosten, 2010; Kobya et al., 2010; Gili, 2015) visando sua aplicação na remoção diferentes poluentes.

O funcionamento de um reator de eletrofloculação baseia-se na existência de eletrodos de sacrifício que geram íons em razão do potencial aplicado. Essa etapa faz parte do processo anódico, onde o metal é oxidado. O íon metálico sofre hidrólise gerando hidróxidos metálicos, iniciando a coagulação, e o transporte das espécies hidrolisadas no meio reacional garante o contato destas com os contaminantes. Com a formação dos complexos do metal, inicia-se o 
processo de floculação, onde ocorre a adsorção dos complexos às partículas coloidais. Esta aglutinação gera partículas maiores, os flocos, que podem então ser retirados por decantação, filtração ou flotação (Crespilho e Rezende, 2004).

Simultaneamente à formação dos íons metálicos, há a formação de gases na forma de microbolhas, que promovem o arraste das partículas coloidais, resultando no fenômeno de flotação. Deste modo, pode-se observar que a eletrofloculação é um processo muito simples. Mediante a aplicação de uma diferença de potencial (ddp), os fenômenos de coagulação, floculação e flotação ocorrem concomitantemente.

Uma das vantagens da eletrofloculação quando comparada à coagulação química tradicional, na qual um agente coagulante é adicionado ao meio (normalmente sulfato de alumínio e/ou cloreto de ferro II) decorre do fato de que esses agentes acabam por gerar compostos químicos nocivos à saúde, o que não ocorre quando o coagulante é gerado in situ. (Crespilho e Rezende, 2004).

Vale ressaltar, em relação aos estudos citados, que a maior parte deles utiliza-se de célula tradicional, em que os eletrodos são duas placas; em alguns casos, conjuntos de placas são utilizados, contudo, segundo Mollah (2004), para tratamentos de efluentes, células com somente dois eletrodos não são recomendados, pois para uma dissolução melhor do metal são necessários eletrodos com grande área superficial. Para sobrepujar esse tipo de limitação, o uso de eletrodos particulados apresenta-se como possibilidade de solução, ainda muito pouco explorada.

Nesse contexto, esse trabalho teve por objetivo a avaliação do uso de reator eletroquímico com anodo de leito fixo constituído por partículas esféricas de ferro no tratamento de efluente têxtil simulado por eletrocoagulação. Foram avaliados os efeitos de $\mathrm{pH}$ e distância entre eletrodos sobre as respostas eficiência de remoção de cor e consumo energético.

\section{MATERIAIS E MÉTODOS}

O efluente simulado foi preparado pela mistura de corante têxtil reativo Azul Royal Tiafix (Aupicor Química) e cloreto de sódio a água destilada, respectivamente, com concentrações de $0,125 \mathrm{~g} \mathrm{~L}^{-1}$ e $1 \mathrm{~g} \mathrm{~L}^{-1}$ e volume total de $2 \mathrm{~L}$. Após a mistura, o $\mathrm{pH}$ era ajustado pela adição de ácido clorídrico (para pH 2) ou hidróxido de sódio (para pH 8).

O sistema utilizado para realização dos experimentos pode ser visto na Figura 1(a), sendo constituído por bomba magnética - Iwaki MD-10K-220 ENL - para circulação do fluido (1), reservatório do efluente (2) com ponto de amostragem de líquido (3), reator eletroquímico com anodo particulado de ferro (4), fonte de corrente - Instrutherm FA-3005 (5), multímetros para medida de corrente e voltagem (6).

O reator (4), mostrado na Figura 1(b), apresentava configuração modular, que permitia a variação da distância (d) entre a placa alimentadora de corrente e o catodo (ambos em aço inoxidável) nos valores de 1,0 e 1,5 cm. O anodo era constituído de leito de $3 \mathrm{~cm}$ de altura de partículas de ferro com diâmetro entre 0,42 e $0,59 \mathrm{~mm}$ e o catodo foi revestido por tela de poliamida para evitar curto-circuito. 


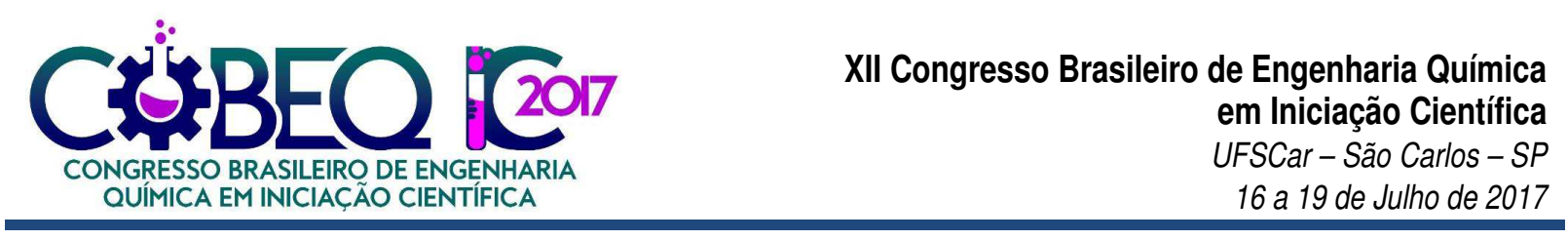

Figura 1 - (a) Sistema experimental, com (b) detalhe do reator eletroquímico.

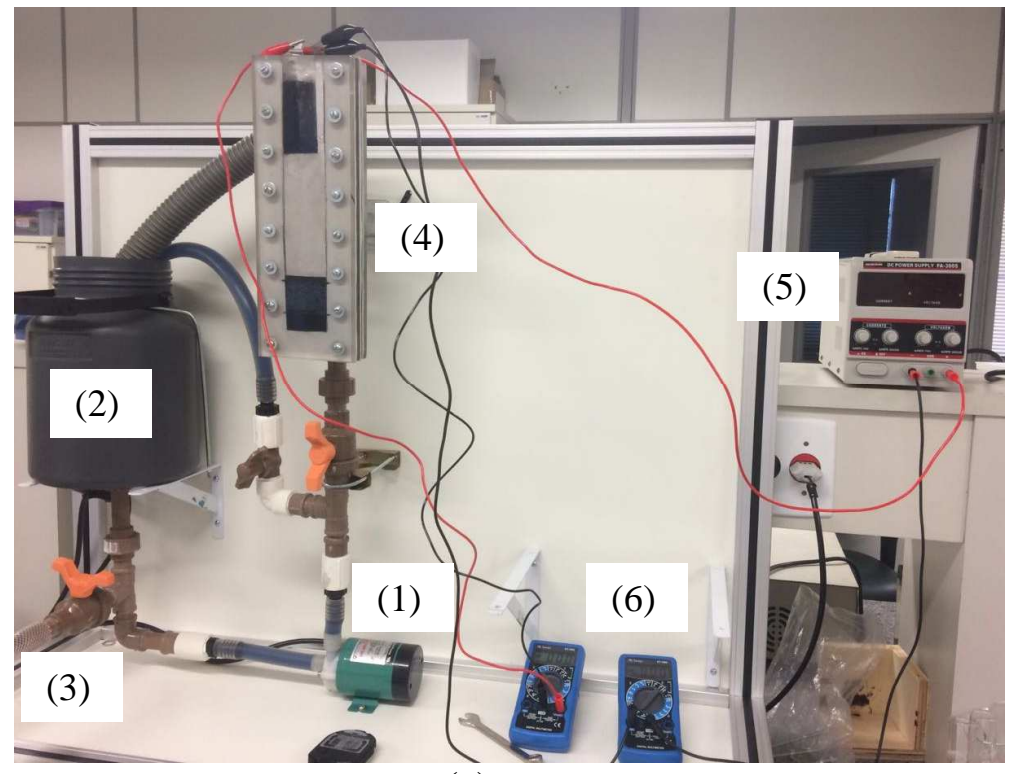

(a)

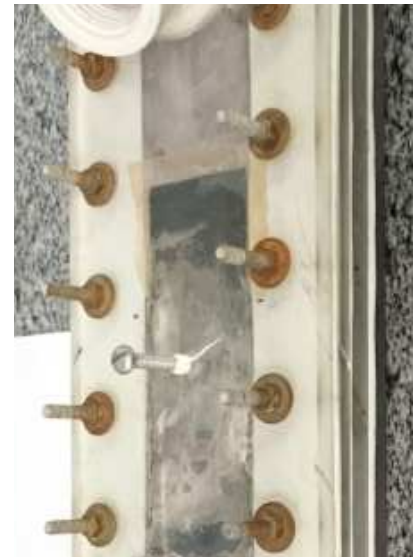

(b)

Após a transferência do efluente sintético no pH ajustado para o reservatório e das partículas de ferro para o interior do reator, a bomba era acionada para circulação do fluido entre o reservatório e o reator e a fonte de corrente ligada. A partir desse instante, a cada 5 minutos os valores de voltagem e corrente eram anotados e uma amostra do fluido era coletada em proveta, na qual era mantida por 30 minutos para sedimentação e, depois, filtrada para análise em espectrofotômetro UV-Visível em comprimento de onda de $613 \mathrm{~nm}$. O tempo total de aplicação de corrente variou entre 15 e 30 minutos, sendo mais curto nos ensaios de $\mathrm{pH}$ ácido pela interrupção do fluxo de efluente ocasionada pela alta de concentração de flocos formados.

Com os dados de absorbância da solução para diferentes tempos de ensaio, calculou-se a eficiência de remoção de corante $\left(\mathrm{E}_{\text {cor }}(\%)\right)$ pela Equação (1):

$$
\mathrm{E}_{\mathrm{cor}}(\%)=\left(\frac{\mathrm{A}_{0}-\mathrm{A}}{\mathrm{A}_{0}}\right) * 100
$$

onde $\mathrm{A}_{0}$ é absorbância inicial do efluente e A é a absorbância do efluente no tempo t.

Foi também avaliado o Consumo Energético (CE) do sistema, utilizando-se a Equação (2):

$$
\mathrm{CE}(\mathrm{W} . \mathrm{h})=\text { U.I.t }
$$

onde U é a voltagem aplicada ao sistema (V); I é a corrente (A) e t o tempo de aplicação da corrente (h). 


\section{RESULTADOS E DISCUSSÕES}

Na Figura 2 são apresentados os resultados para a eficiência de remoção de corante $\mathrm{E}_{\mathrm{cor}}(\%)$ - em função do tempo para as diferentes condições experimentais.

Figura 2 - Eficiência de remoção de cor em função do tempo para diferentes valores de pH e distância entre eletrodos.

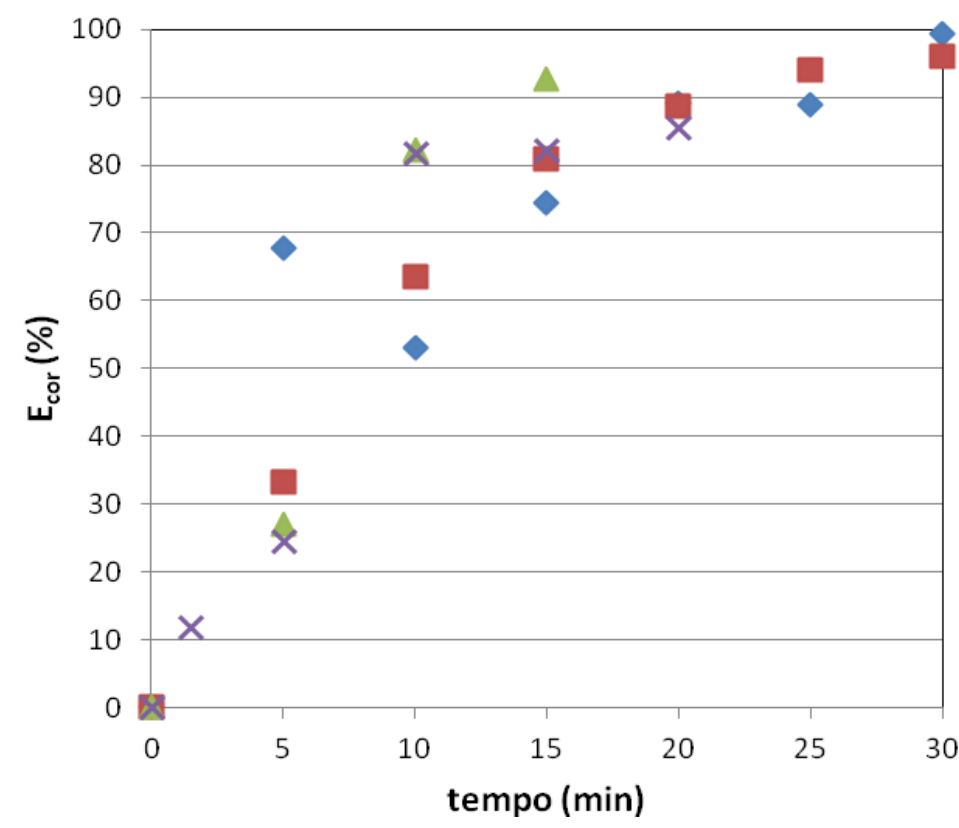

$\checkmark \mathrm{pH}=8$, distância $=1,0 \mathrm{~cm}$

口 $\mathrm{pH}=8$; distância $=1,5 \mathrm{~cm}$

$\Delta \mathrm{pH}=2$; distância $=1,0 \mathrm{~cm}$

$\times \mathrm{pH}=2$; distância $=1,5 \mathrm{~cm}$

Observa-se, na Figura 2, que a eficiência de remoção de cor aumenta com o tempo de operação, o que era esperado, uma vez que, quanto maior o tempo de operação, maior será a formação de agentes coagulantes a partir da dissolução do anodo de ferro, os quais são responsáveis pela remoção da coloração do efluente líquido a partir da coagulação e sedimentação das moléculas orgânicas do corante.

Como já relatado em Métodos, não foi possível a continuação dos experimentos por mais de 15 e 20 minutos quando se ajustou o pH em 2, uma vez que ocorreu a interrupção do fluxo de eletrólito pela obstrução do reator pelos flocos formados. Dessa forma, a comparação entre todas as situações experimentais só é possível até 15 minutos.

Considerando o tempo até 15 minutos, observou-se tipicamente uma maior eficiência na remoção de corante quando da utilização do menor valor de $\mathrm{pH}$ e da menor distância entre eletrodos. Contudo, é possível observar, na Figura 2, que nos experimentos com pH ajustado em 8, em que foi possível a operação até 30 minutos, percentuais de remoção tão ou mais elevados são alcançados, mas mais lentamente.

Utilizando-se valores médios de corrente e voltagem, calculou-se, utilizando-se a Equação (2), o consumo energético (CE) para 15 minutos de operação para todas as condições experimentais, uma vez que esse parâmetro está diretamente relacionado ao custo de operação. Os resultados encontram-se na Tabela 1. 
Tabela 1 - Valores médios de voltagem, corrente e consumo energético e porcentagem de remoção de corante para 15 minutos de operação nas diferentes condições experimentais.

\begin{tabular}{ccccc}
\hline & $\begin{array}{c}\mathbf{p H}=\mathbf{2} \\
\mathbf{d}=\mathbf{1 , 0} \mathbf{~ c m}\end{array}$ & $\begin{array}{c}\mathbf{p H}=\mathbf{2} \\
\mathbf{d = 1 , 5} \mathbf{~ c m}\end{array}$ & $\begin{array}{c}\mathbf{p H}=\mathbf{8} \\
\mathbf{d = 1 , 0} \mathbf{~ c m}\end{array}$ & $\begin{array}{c}\mathbf{p H}=\mathbf{8} \\
\mathbf{d = 1 , 5} \mathbf{~ c m}\end{array}$ \\
\hline $\mathrm{I}_{\text {médio }}(\mathrm{A})$ & 3,54 & 2,70 & 2,30 & 1,64 \\
\hline $\mathrm{U}_{\text {médio }}(\mathrm{V})$ & 31,38 & 31,63 & 32,90 & 31,90 \\
\hline $\mathrm{CE}_{\text {médio }}(\mathrm{W} . \mathrm{h})$ & 27,8 & 21,3 & 18,9 & 13,1 \\
\hline $\mathrm{E}_{\text {cor }}(\%)$ & 93 & 82 & 74 & 81 \\
\hline
\end{tabular}

Pode-se perceber, pelos resultados apresentados na Tabela 1, que a despeito de se alcançar mais rapidamente valores elevados de remoção de cor quando da utilização do menor valor de $\mathrm{pH}$, especialmente para a distância de 1,0 cm (93\% de remoção em 15 minutos), essa condição apresentou também o mais alto valor de consumo energético, implicando em custo mais elevado de operação.

Embora se tenha, para o caso de pH 8 e distância de $1,5 \mathrm{~cm}$, um percentual de remoção de cor $13 \%$ menor (81\%), seu consumo energético é $53 \%$ menor do que o observado para a condição de maior remoção de cor em 15 minutos (13,1 W.h comparado a 27,8 W.h).

Portanto, a menos que a rapidez na operação seja imperiosa, as condições que levam a menor custo energético em 15 minutos são as de $\mathrm{pH}$ básico, em especial para distância de $1,5 \mathrm{~cm}$ entre catodo e placa alimentadora de corrente.

Com o objetivo de se conseguir comparação mais direta do custo nas diferentes condições para os mesmos 15 minutos de operação, utilizou-se dos valores de $\mathrm{E}_{\text {cor }} \mathrm{e}$ da concentração inicial de corante para se estimar a massa de corante retirada do efluente e, sabendo-se o consumo energético, estimou-se o custo para a remoção de $1 \mathrm{~kg}$ de corante em cada caso. Os resultados encontram-se na Tabela 2.

Tabela 2 - Custo para remoção de corante, considerando-se 15 minutos de operação nas diferentes condições experimentais.

\begin{tabular}{ccccc}
\hline & $\begin{array}{c}\mathbf{p H}=\mathbf{2} \\
\mathbf{d = 1 , 0} \mathbf{~ c m}\end{array}$ & $\begin{array}{c}\mathbf{p H}=\mathbf{2} \\
\mathbf{d = 1 , 5} \mathbf{~ c m}\end{array}$ & $\begin{array}{c}\mathbf{p H}=\mathbf{8} \\
\mathbf{d = 1 , 0} \mathbf{~ c m}\end{array}$ & $\begin{array}{c}\mathbf{p H}=\mathbf{8} \\
\mathbf{d = 1 , 5} \mathbf{~ c m}\end{array}$ \\
\hline Massa de corante removida (g) & 0,116 & 0,103 & 0,093 & 0,101 \\
\hline $\mathrm{CE}_{\text {médio }}(\mathrm{W} . \mathrm{h})$ & 27,8 & 21,3 & 18,9 & 13,1 \\
\hline $\begin{array}{c}\text { Custo de energia por kg de } \\
\text { corante }(\mathrm{R} \$ / \mathrm{kg} \text { ) }\end{array}$ & 43,24 & 37,31 & 36,66 & 23,40 \\
\hline
\end{tabular}

* Considerou-se valor de R \$0,1804/kW.h, fornecido pela Eletropaulo em dez/2016.

Fica claro, pelos resultados mostrados na Tabela 2, o menor custo para remoção da mesma quantidade de corante quando da utilização do $\mathrm{pH}$ básico e distância de $1,5 \mathrm{~cm}$.

\section{CONCLUSÕES}

O uso de reator eletroquímico com anodo de leito fixo mostrou-se bastante eficiente no tratamento de efluente têxtil simulado, obtendo-se percentuais de remoção do corante superiores a $90 \%$ com tempo de operação entre 15 e 30 minutos. 
Em relação ao efeito do pH sobre as respostas estudadas, no pH ácido se alcançaram mais rapidamente altas eficiências de remoção, contudo, valores mais elevados de consumo energético foram observados, em comparação ao observado no pH básico.

O aumento da distância entre placa alimentadora de corrente e catodo levou ao aumento da porcentagem de remoção no caso do $\mathrm{pH}$ básico, mas reduziu a porcentagem de remoção quando do uso do pH ácido. Em relação ao consumo energético, o aumento da distância de 1,0 para $1,5 \mathrm{~cm}$ levou à redução do consumo em ambos os valores de $\mathrm{pH}$.

Estimando-se o custo para remoção de $1 \mathrm{~kg}$ de corante nas condições obtidas para 15 minutos de operação, o menor custo $(\mathrm{R} \$ 23,40 / \mathrm{kg}$ ) foi obtido para $\mathrm{pH}=2$ e distância de $1,5 \mathrm{~cm}$.

\section{REFERÊNCIAS}

ABIT. Perfil do Setor. Disponível em: <http://www.abit.org.br/cont/perfil-do-setor>. Acesso em 20 out. 2016.

CRESPILHO, F. N.; REZENDE, M. O. O. Eletroflotação: Princípios e Aplicações. São Carlos: Rima, 2004.

FORMENTINI, D.F. Tratamento Eletroquímico de Esgotos Sanitários. Dissertação (Mestrado em Energia na Agricultura) - Universidade Estadual do Oeste do Paraná, Cascavel, 2012.

GILI, I. Tratamento de Efluentes por Eletrólise: Estudo de Caso para Efluentes Têxteis. 2015. 102 f. Dissertação (Mestrado em Engenharia química) - Universidade Federal de Santa Catarina, 2015.

KILIÇ, M. G.; HOSTEN, Ç. A comparative study of electrocoagulation and coagulation of aqueous suspensions of kaolinite powders. J. Hazard. Mater., p. 735-740, 2010.

KOBYA, M.; DEMIRBAS, E.; SÖZBIR, M.Decolorisation of aqueous reactive dye Remazol Red 3B by electrocoagulation. Coloration Technology. p. 282-288. out. 2012.

KUNZ, A. et al. Novas tendências no tratamento de efluentes têxteis. Química Nova. v. 25, n. 1, p.78-82, jun. 2002.

MOLLAH, M. Y. A. et al. Fundamentals, present and future perspectives of electrocoagulation. J. Hazard. Mater., p. 199-210, 2004. 